\title{
Comparative Study of Power Factor Correction Converters For Single Phase Half-Bridge Inverters
}

\author{
Gui-Jia Su, Senior Member, IEEE, Donald J. Adams, Leon M. Tolbert, Senior Member, IEEE \\ Oak Ridge National Laboratory \\ National Transportation Research Center \\ Knoxville, Tennessee 37932 \\ Email: sugj@ornl.gov
}

\begin{abstract}
Half-bridge inverter is very suitable for singlephase on-line UPS applications because it offers very desirable features. These include fewer active switches, a common neutral connection - not requiring an isolation transformer, and sinusoidal input currents if a power factor correction (PFC) converter is used at the front end. This paper presents a comparative study of PFC converters for single-phase half-bridge UPS inverters. A traditional half-bridge converter and two recently introduced ac-dc/dc-dc boost converters are comparatively investigated for active switch count, voltage stresses on the switches, and capability of voltage balance control of the de bus capacitors. Analytical and experimental results are included in this paper to illustrate performance differences among the converters in terms of input current harmonic distortion and energy efficiency.
\end{abstract}

\section{INTRODUCTION}

Uninterruptible power supply (UPS) systems are being widely used for a variety of critical loads including computers, telecommunication systems and medical equipment to overcome disruptions in utility power such as outage, voltage sag or voltage surge. Although UPSs have been applied for large computers, the large installation number of small or personal computers (PCs) has created a tremendous increase in the use of small capacity UPSs operating off a single-phase supply. To match the decreased cost of PC computing capability, these single-phase UPSs are extremely sensitive to cost.

On-line systems are preferred where a highly reliable uninterruptible power supply is required. Among various topologies for on-line UPS systems up to $5 \mathrm{kVA}$ reported in the literature [1][2], UPS systems based on a half bridge diode rectifier combined with a half bridge inverter, as shown in Fig. 1, have attracted attention for applications in computer and telecommunication systems. Compared with systems based on full bridge converters with a high frequency or commercial ac line frequency isolation transformer [3], the

\footnotetext{
* Prepared by Oak Ridge National Laboratory, managed by UT-Battelle, LLC, for the U.S. Dept. of Energy under contract DE-AC05-00OR22725. The submitted manuscript has been authored by a contractor of the U.S. Government under contract DE-AC05-00OR22725. Accordingly, the U.S. Government retains a nonexclusive, royalty-free license to publish or reproduce the published form of this contribution, or allow others to do so, for U.S. Government purposes.
}

half-bridge topology offers several advantages including a simple power conversion circuit with possibly the lowest switching device count and no isolation transformer. Adding other desirable features such as sinusoidal ac line currents with unity power factor and load regulation with non-linear loads, the half bridge topology provides the potential for compact, low cost and high performance systems.

The system shown in Fig. 1, however, has two major disadvantages. The diode rectifier on the front end causes serious harmonic pollution to the utility as the number of UPSs increases. The other disadvantage resultes from the direct connection of the storage battery to the dc bus. Many battery cells connected in series are required to support a high dc bus voltage, which is about twice the peak line voltage. This requirement of a high voltage storage battery leads to increased cost and reduced reliability, since for a given storage capacity the cost rises but the reliability decreases as the number of storage batteries increases.

A straightforward way to address the harmonic problem is to employ a half-bridge converter to replace the diode rectifier, as shown in Fig. 2. The remaining high voltage battery storage requirement, however, becomes worse, because the $\mathrm{dc}$

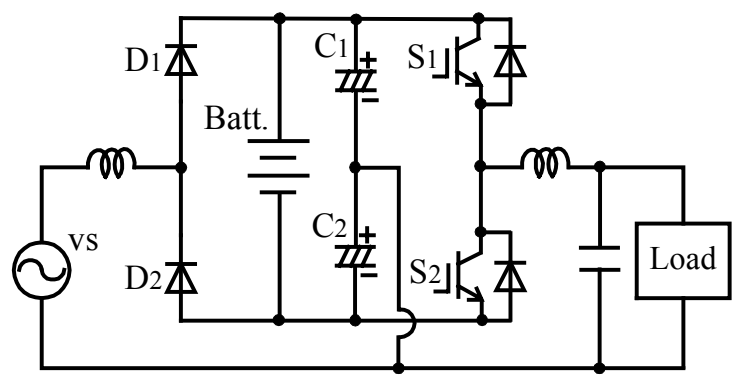

Fig. 1 Single-phase UPS system based on a diode rectifier and a halfbridge inverter.

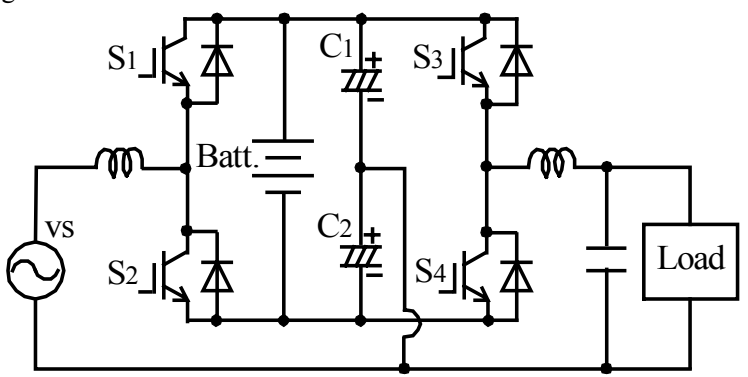

Fig. 2 Single-phase UPS system based on a half-bridge converter and inverter. 
bus voltage has to be raised even higher to shape the input current waveform.

Several schemes have been reported to overcome the high battery voltage issue. One approach is to add one more phase leg to the dc bus, which forms a bi-directional chopper circuit for connecting a low voltage battery to the dc bus [4][5], as shown in Fig. 3 (a). The bi-directional chopper steps down the dc bus voltage for charging the battery, or steps up the battery voltage to support the dc bus during ac line outages. A low voltage battery can thus be adapted at the expense of a bi-directional chopper. Moreover, all six switches are exposed to a boosted high dc bus voltage - around $350 \mathrm{~V}$ for a $100 \mathrm{~V}$ ac line, causing increased voltage stress and switching losses.

Taking advantage of the fact that net power flow in most UPS applications is unidirectional from ac line to load, new approaches have been proposed to develop single-phase online UPS systems. A single switch boost converter performing ac-dc conversion during normal operation or dc-dc conversion during battery powered operation is introduced in [6] and shown in Fig.3(b), to replace the diode rectifier and the high voltage battery in Fig. 1. Combined with a half bridge inverter for dc-ac conversion, this topology maintains the benefits inherent in the half bridge scheme and provides other desirable features such as reduced switch count (only four active switches) and low voltage battery. The drawback of the scheme is that it is incapable of correcting possible capacitor voltage unbalance during battery powered operation. Another new boost converter, shown in Fig.3(c), is proposed in [7] to overcome the drawback of the scheme in [6]. The new converter uses only four active switches and allows full control of the ac line currents, load voltages, battery discharge regulations, and voltage unbalance correction of dc bus capacitors. An additional switch can be added to charge the battery.

This paper presents a comparative study of these three power factor correction (PFC) converters for single-phase half-bridge inverters in UPS applications.

\section{PFC CONVERTERS FOR HALF-BRIDGE INVERTER IN SINGLE PHASE UPS SYSTEMS}

\section{A. Description of the Single Phase UPS Systems with the PFC Converters}

Fig. 3 shows simplified schematics of the three UPS systems with the PFC converters enclosed with a dashed box. Fig. 3(a) illustrates the traditional system that employs a halfbridge converter for power factor correction and a bidirectional dc-dc converter for battery charge/discharge regulation.

Fig. 3(b) shows one of the recently introduced systems employing a single active switch ac-dc/dc-dc converter. Switch $\mathrm{S}_{1}$ and inductor $\mathrm{L}_{1}$ plus diodes $\mathrm{D}_{1} \sim \mathrm{D}_{6}$ form an ac-dc boost converter to synthesize sinusoidal ac line currents when operating off an ac line, or a dc-dc boost converter to support the dc link voltage from the storage battery during line outages. A single-switch step-down chopper for charging the

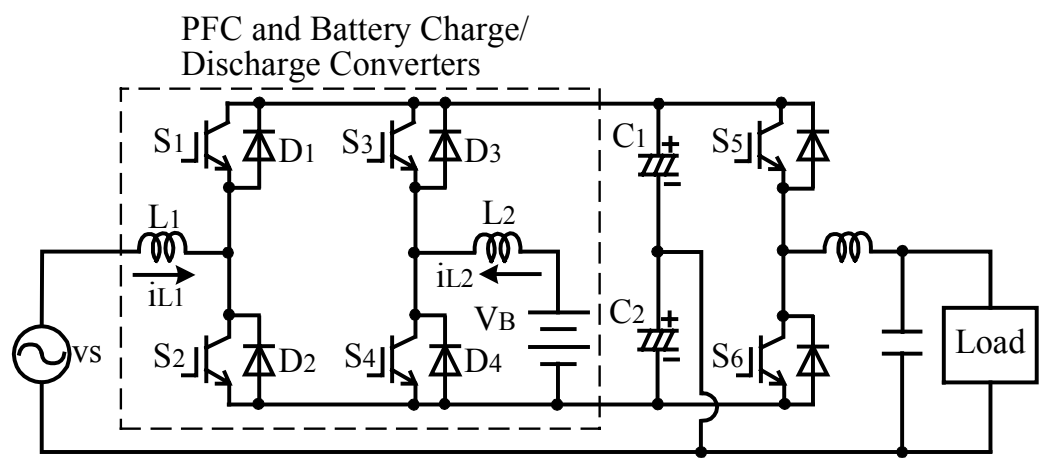

(a) A conventional system with a half-bridge PFC converter and a battery charge/discharge converter

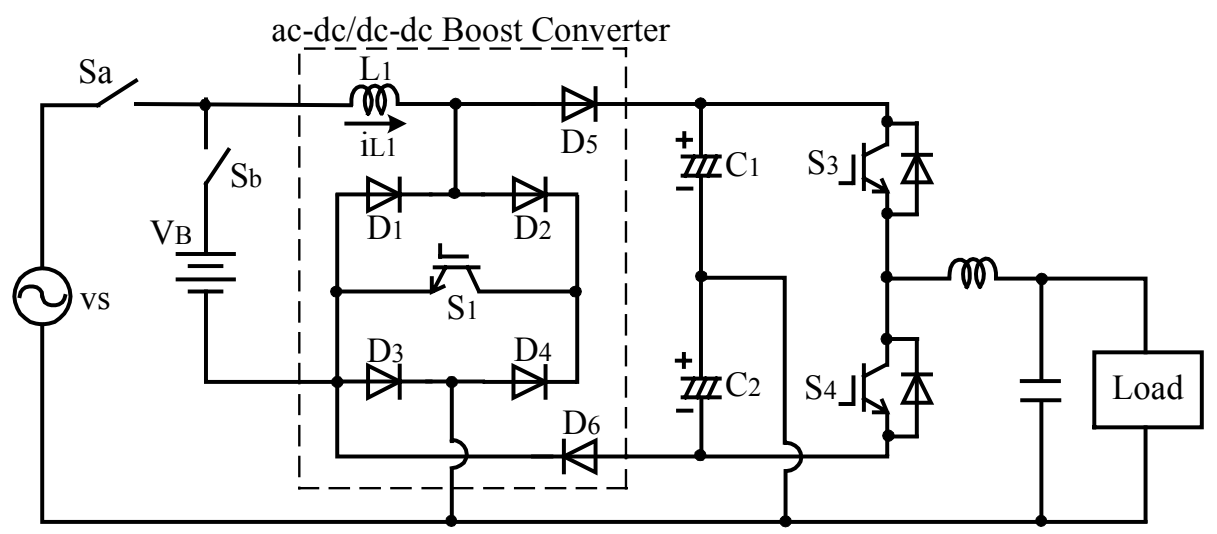

(b) A newly introduced system with a single-switch ac-dc/dc-dc boost converter Fig. 3 Schematics of single-phase UPS systems. 


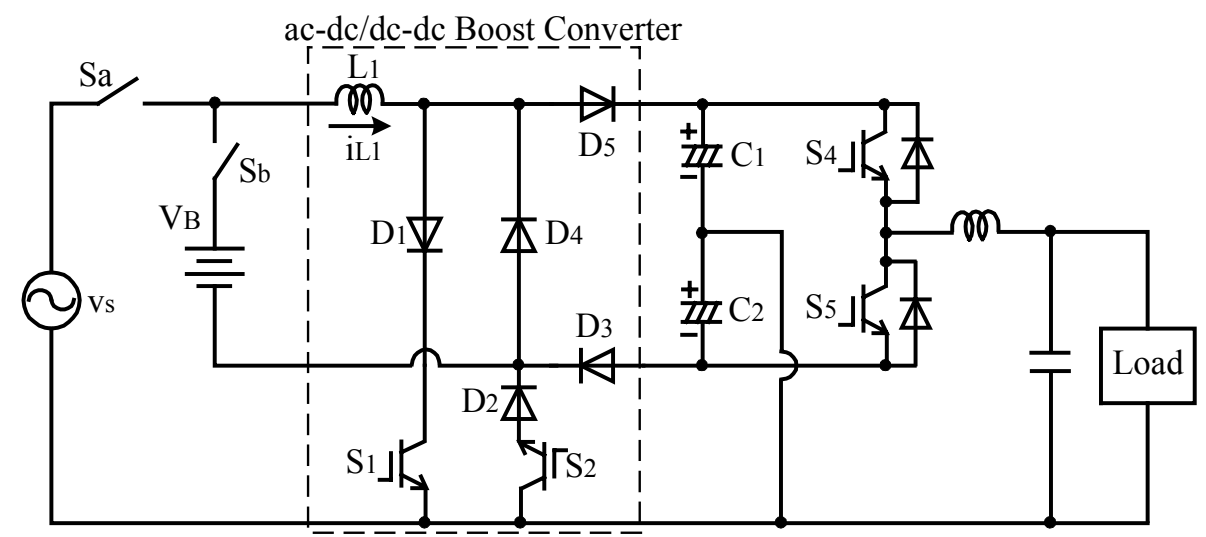

(c) A newly introduced system with a two-switch ac-dc/dc-dc boost converter.

Fig. 3 Schematics of single-phase UPS systems (cont'd).

storage battery, which is not shown in the figure for simplicity, is required.

Fig. 3(c) depicts the other system which employs a twoactive-switch ac-dc/dc-dc converter. Switches $\mathrm{S}_{1}, \mathrm{~S}_{2}$ and inductor $\mathrm{L}_{1}$ plus diodes $\mathrm{D}_{1} \sim \mathrm{D}_{5}$ form an ac-dc boost converter to force ac line currents of sinusoidal waveform when operating off ac line, or a dc-dc boost converter to support the dc bus voltage from the storage battery during line outages. Again, a single-switch step-down chopper not shown in the figure is used to charge the storage battery. It should be mentioned that the two diodes $\left(D_{1}\right.$ and $\left.D_{2}\right)$ can be removed if voltage-controlled switching devices with reverse voltage blocking capability become commercially available, thus further reducing parts count and cost.

Two transfer switches, $\mathrm{S}_{\mathrm{a}}$ and $\mathrm{S}_{\mathrm{b}}$, are used in Fig. 3(b) and Fig. 3(c) to transfer the input to the boost converter between the ac line and storage battery. Either static switches or electromagnetic contacts may be used.

\section{B. Half-Bridge Converter Operation Modes}

The operation of the PFC converter in the conventional system shown in Fig. 3(a) is straightforward. When operating off the ac line, for positive line voltage $v_{s}$, turning on switch $\mathrm{S}_{2}$ increases the current, $i_{L 1}$, in the inductor $\mathrm{L}_{1}$ according to the following equation,

$$
\mathrm{S}_{2} \text { on: } v_{s}+V_{C 2}=L_{1} \frac{d i_{L 1}}{d t}
$$

and turning off $\mathrm{S}_{2}$ decreases the inductor current according to the equation below,

$$
\mathrm{S}_{2} \text { off: } v_{s}-V_{C 1}=L_{1} \frac{d i_{L 1}}{d t}
$$

Similar operations can be derived for a negative line voltage with the switch $\mathrm{S}_{1}$ controlling the inductor current. Moreover, switch $\mathrm{S}_{3}$ is employed to regulate the battery charge.

When operating off the battery during line outages, the switch $\mathrm{S}_{4}$ is PWM controlled to maintain the dc bus voltage.

$$
\begin{aligned}
& \mathrm{S}_{4} \text { on: } V_{B}=L_{2} \frac{d i_{L 2}}{d t} \\
& \mathrm{~S}_{4} \text { off: } V_{B}-V_{C 1}-V_{C 2}=L_{2} \frac{d i_{L 2}}{d t}
\end{aligned}
$$

It is apparent that all the four switches are subject to the dc bus voltage during the off state with the other switch on the same phase leg on. This leads to higher switching loss and voltage stress compared to the other converters. Furthermore, the capacitor voltage is involved in boosting the inductor current as indicated by Eq. (1), causing a higher current ripple and total harmonic distortion factor.

\section{Single-Switch Converter Operation Modes}

The operation of the single-switch ac-dc/dc-dc PFC converter in Fig. 3(b) can be divided into four normal operation modes for operating off the ac line and two battery powered modes for operating during ac line outages.

1) Normal operation modes (switch $\mathrm{S}_{\mathrm{a}}$ is kept on and $\mathrm{S}_{\mathrm{b}}$ off): The current in the inductor $\mathrm{L}_{1}$ is regulated by PWM control of the ac-dc boost converter to obtain a sinusoidal ac line current while maintaining a constant voltage across the dc link capacitors.

For positive ac line voltage $\mathrm{v}_{\mathrm{S}}$ if switch $\mathrm{S}_{1}$ is turned on, a current is produced in the path of $\mathrm{v}_{\mathrm{S}} \rightarrow \mathrm{L}_{1} \rightarrow \mathrm{D}_{2} \rightarrow \mathrm{S}_{1} \rightarrow \mathrm{D}_{3}$ $\rightarrow \mathrm{v}_{\mathrm{S}}$, storing energy in the inductor $\mathrm{L}_{1}$.

$$
\mathrm{S}_{1} \text { on: } v_{S}=L_{1} \frac{d i_{L 1}}{d t}
$$

Then turning off $\mathrm{S}_{1}$ changes the current path to transfer power from the ac line to dc bus and to release part of the stored energy. A current is provided for charging the upper dc capacitor $\mathrm{C}_{1}$ through the path of $\mathrm{v}_{\mathrm{s}} \rightarrow \mathrm{L}_{1} \rightarrow \mathrm{D}_{5} \rightarrow \mathrm{C}_{1} \rightarrow \mathrm{v}_{\mathrm{s}}$.

$$
\mathrm{S}_{1} \text { off: } v_{S}-V_{C 1}=L_{1} \frac{d i_{L 1}}{d t}
$$

Similarly, for negative $v_{s}$ two other operation modes can be established. With $S_{1}$ off, the lower dc capacitor $C_{2}$ is charged during these modes with a current flowing in the path of $\mathrm{v}_{\mathrm{S}} \rightarrow$ $\mathrm{C}_{2} \rightarrow \mathrm{D}_{6} \rightarrow \mathrm{D}_{1} \rightarrow \mathrm{L}_{1} \rightarrow \mathrm{v}_{\mathrm{s}}$. 
2) Battery powered operation modes: Upon identifying failure of ac line, switch $\mathrm{S}_{\mathrm{a}}$ is turned off and $\mathrm{S}_{\mathrm{b}}$ on, transferring the input from the ac line to the storage battery for the boost converter, which now functions as a dc-dc step-up chopper to continue supplying the load. To support the dc link voltage, switch $S_{1}$ is first turned on to generate a current through the path of $\mathrm{V}_{\mathrm{B}} \rightarrow \mathrm{L}_{1} \rightarrow \mathrm{D}_{2} \rightarrow \mathrm{S}_{1} \rightarrow \mathrm{V}_{\mathrm{B}}$ and store energy in the inductor $L_{1}$.

$$
\mathrm{S}_{1} \text { on: } V_{B}=L_{1} \frac{d i_{L 1}}{d t}
$$

After $S_{1}$ is turned off, part of the stored energy in the battery and $\mathrm{L}_{1}$ is then transferred to the load through the dc bus, and a current for charging the dc capacitors is produced in the path of $\mathrm{V}_{\mathrm{B}} \rightarrow \mathrm{L}_{1} \rightarrow \mathrm{D}_{5} \rightarrow \mathrm{C}_{1} \rightarrow \mathrm{C}_{2} \rightarrow \mathrm{D}_{6} \rightarrow \mathrm{V}_{\mathrm{B}}$.

$$
\mathrm{S}_{1} \text { off: } V_{B}-V_{C 1}-V_{C 2}=L_{1} \frac{d i_{L 1}}{d t}
$$

It is clear that for normal operation modes the switch $\mathrm{S}_{1}$ is subject to only half the dc bus voltage during the off state, leading to reduced switching loss and voltage stress compared to the half-bridge converter. Furthermore, the capacitor voltage is not involved in boosting the inductor current as indicated in Eq. (5), producing a lower current ripple and total harmonic distortion factor.

\section{Two-Switch Converter Operation Modes}

Similarly, the operation of the two-switch ac-dc/dc-dc boost converter in Fig. 3(c) can be divided into four normal operation modes for operating off the ac line and three battery powered modes for operating during ac line outages.

1) Normal operation modes (switch $\mathrm{S}_{\mathrm{a}}$ is kept on and $\mathrm{S}_{\mathrm{b}}$ off): The current in the inductor $\mathrm{L}_{1}$ is forced to follow a sinusoidal template by the PWM control of the ac-dc boost converter while maintaining a constant dc bus voltage. Switch $S_{1}$ is used for current regulation during the positive half cycles of the ac line voltage $\mathrm{v}_{\mathrm{S}}$ and switch $\mathrm{S}_{2}$ is used during the negative half cycles.

If switch $\mathrm{S}_{1}$ is turned on for positive $\mathrm{v}_{\mathrm{S}}$, a current is produced in the path of $\mathrm{v}_{\mathrm{S}} \rightarrow \mathrm{L}_{1} \rightarrow \mathrm{D}_{1} \rightarrow \mathrm{S}_{1} \rightarrow \mathrm{v}_{\mathrm{s}}$, storing energy in the inductor $L_{1}$. Then turning off $S_{1}$ changes the current path and transfers power from the ac line to dc bus. A current is provided for charging the upper dc capacitor $\mathrm{C}_{1}$ through the path of $\mathrm{v}_{\mathrm{s}} \rightarrow \mathrm{L}_{1} \rightarrow \mathrm{D}_{5} \rightarrow \mathrm{C}_{1} \rightarrow \mathrm{v}_{\mathrm{s}}$.

$$
\begin{aligned}
& \mathrm{S}_{1} \text { on: } v_{S}=L_{1} \frac{d i_{L 1}}{d t} \\
& \mathrm{~S}_{1} \text { off: } v_{S}-V_{C 1}=L_{1} \frac{d i_{L 1}}{d t}
\end{aligned}
$$

Similarly, for negative $\mathrm{v}_{\mathrm{S}}$ two other operation modes can be established by the control of switch $\mathrm{S}_{2}$. With $\mathrm{S}_{2}$ off, the lower dc capacitor $\mathrm{C}_{2}$ is charged during these modes with a current flowing in the path of $\mathrm{v}_{\mathrm{s}} \rightarrow \mathrm{C}_{2} \rightarrow \mathrm{D}_{3} \rightarrow \mathrm{D}_{4} \rightarrow \mathrm{L}_{1} \rightarrow \mathrm{v}_{\mathrm{s}}$.
2) Battery powered operation modes: Upon identifying failure of the ac line, switch $\mathrm{S}_{\mathrm{a}}$ is turned off and $\mathrm{S}_{\mathrm{b}}$ on, transferring the input from the ac line to the storage battery for the boost converter, which now functions as a dc-dc step-up chopper. To support the dc bus voltage, both switches $S_{1}$ and $\mathrm{S}_{2}$ are first turned on, generating a current through the path of $\mathrm{V}_{\mathrm{B}} \rightarrow \mathrm{L}_{1} \rightarrow \mathrm{D}_{1} \rightarrow \mathrm{S}_{1} \rightarrow \mathrm{S}_{2} \rightarrow \mathrm{D}_{2} \rightarrow \mathrm{V}_{\mathrm{B}}$ and storing energy in the inductor $\mathrm{L}_{1}$. To avoid charging the two dc bus capacitors simultaneously thus preventing unbalanced capacitor voltages and to reduce voltage stresses on the switches, only one of the two switches is turned off. Selection of which one to turn off depends on which of the two capacitors needs to be charged. To charge the upper capacitor $\mathrm{C}_{1}, \mathrm{~S}_{1}$ is turned off. Part of the energy stored in the battery and $\mathrm{L}_{1}$ is then transferred to the load through the dc bus, and a current for charging the upper dc bus capacitor is produced following the path of $\mathrm{V}_{\mathrm{B}} \rightarrow \mathrm{L}_{1} \rightarrow \mathrm{D}_{5} \rightarrow \mathrm{C}_{1} \rightarrow \mathrm{S}_{2} \rightarrow \mathrm{D}_{2} \rightarrow \mathrm{V}_{\mathrm{B}}$. Otherwise, $\mathrm{S}_{2}$ is turned off for charging the lower capacitor $\mathrm{C}_{2}$. The charging current is produced in the path of $\mathrm{V}_{\mathrm{B}} \rightarrow \mathrm{L}_{1} \rightarrow \mathrm{D}_{1}$ $\rightarrow \mathrm{S}_{1} \rightarrow \mathrm{C}_{2} \rightarrow \mathrm{D}_{3} \rightarrow \mathrm{V}_{\mathrm{B}}$.

$$
\begin{aligned}
& \mathrm{S}_{1} \& \mathrm{~S}_{2} \text { on: } V_{B}=L_{1} \frac{d i_{L 1}}{d t} \\
& \mathrm{~S}_{1} \text { off } \& \mathrm{~S}_{2} \text { on: } V_{B}-V_{C 1}=L_{1} \frac{d i_{L 1}}{d t} \\
& \mathrm{~S}_{1} \text { on } \& \mathrm{~S}_{2} \text { off: } V_{B}-V_{C 2}=L_{1} \frac{d i_{L 1}}{d t}
\end{aligned}
$$

The switches $S_{1}$ and $S_{2}$ are subjected to only half the dc bus voltage during the normal and battery powered operations. In addition, no de bus capacitor is involved in boosting the inductor current $i_{L I}$. Furthermore, the capability of selectively charging the dc bus capacitors is another important feature of the two-switch boost converter since the two capacitor voltages can now be kept well balanced even if a load draws an unbalanced power for the positive and negative half cycles, which may occur during a load transient.

\section{E. Comparison of the PFC Converters}

Table 1 summarizes the above analysis and gives a comparison of the three PFC converters.

The single- and two-switch boost converters provide several advantages over the half-bridge converter worth of mentioning. The boost converters possess no possibility of shootthrough which may happen in the half bridge converter. Voltage stresses on the active switches of the boost converters are reduced to half dc bus voltage, while conventional halfbridge converter switches are all exposed to full dc bus voltage. This is also true for the diodes. Consequently, we expected to reduce the switching losses and the diode reverse recovery losses, and to improve the reliability. In fact, the acdc conversion efficiency of the boost converters is higher that that of the half-bridge converter despite their additional diodes, as will be shown later. In addition, the two-switch converter has slightly higher efficiency than the single-switch 
version because the current passes one diode in the former converter when $\mathrm{S}_{1}$ is on while it passes two diodes in the latter one.

The capability of balancing dc bus capacitor voltages for both normal and battery operation modes enables the twoactive-switch boost converter to supply asymmetrical loads such as half-wave rectifiers.

\section{Performance CoMparison Based on EXPERIMENTAL RESULTS}

$1 \mathrm{kVA}$ UPS prototypes based on the three converters were built to measure performance data. The UPS system designs considered cost, efficiency, and complexity. IGBTs were used at a switching frequency of $18 \mathrm{kHz}$, and a battery bank with a rated voltage of $48 \mathrm{~V}$ was employed to demonstrate operating performances during ac line outages. The dc bus voltage was set at $360 \mathrm{~V}$ to guarantee a high power factor for the specified range of input line voltages (100Vrms, $+10 \%,-15 \%)$. Selection of the inductance of $\mathrm{L}_{1}$ was based on the ripple requirements when operating from the low voltage battery since it produces higher current ripple than the normal operation modes.

Fig. 4 shows typical source voltage and input current waveforms for the single-switch and two-switch boost converters, demonstrating sinusoidal current waveforms for both converters.

Fig. 5 plots a detailed comparison of measured input power factor $(\mathrm{PF})$ versus output power. At rated output power, the input power factors are about the same for all three converters. However, it deteriorates fast as the output power of the half-bridge converter decreases. Both the single- and two-switch boost converters offer higher power factor as load decreases, which is a desirable feature for applications where UPSs often operate routinely at loads much lower than its rated capacity. The half-bridge converter also produces higher current total harmonic distortion.

Fig. 6 depicts a comparison of measured overall ac-ac conversion efficiency for resistive loads. The two-switch converter has the highest efficiency at a given output, and both the boost converters produce higher efficiency than the halfbridge converter. The maximum efficiency is $87.1 \%$ for the half-bridge converter system, 87.4 for the single-switch con- verter, and $87.7 \%$ for the two-switch converter systems. Again, the boost converters gain more improvement in efficiency over the half-bridge converter as load power decreases. This is due to the increasing weight of switching loss against conduction loss as the load power decreases.

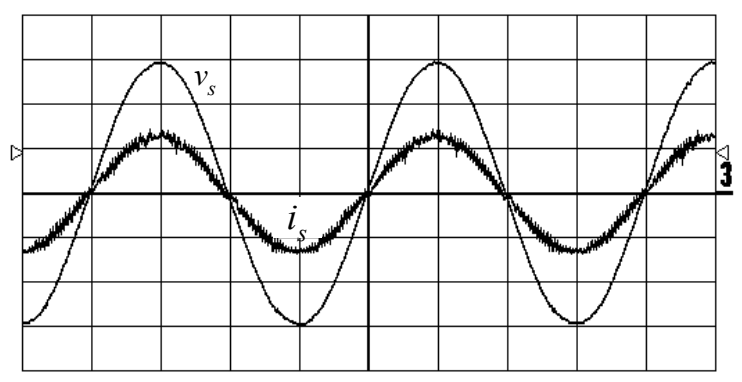

(a) Single-switch boost converter.

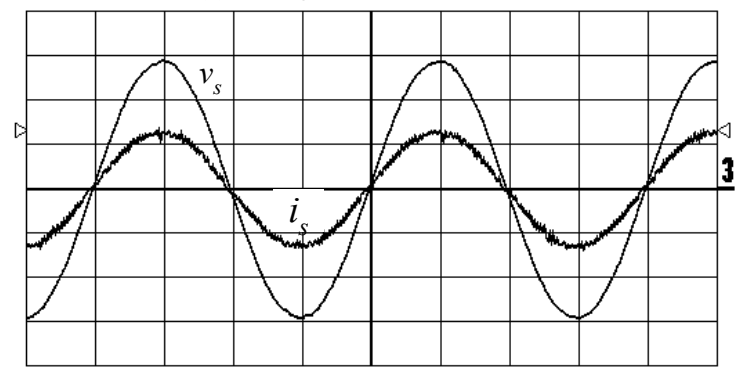

(b) Two-switch boost converter.

Fig.4. Source voltage, $v_{s}(50 \mathrm{~V} /$ div $)$ and current, $i_{s}(10 \mathrm{~A} /$ div $)$ waveforms. Time scale: $5 \mathrm{~ms} / \mathrm{div}$.

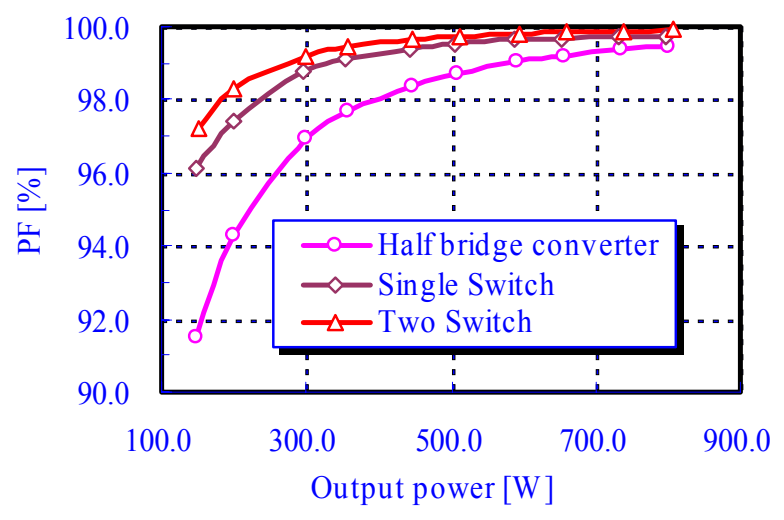

Fig. 5 Comparison of measured PF vs. output power.

TABLE I.

Comparison of the three PFC converters.

\begin{tabular}{|c|c|c|c|c|}
\hline & $\begin{array}{l}\text { Half-bridge } \\
\text { converter }\end{array}$ & $\begin{array}{l}\text { Single active switch ac- } \\
\text { dc/dc-dc boost converter }\end{array}$ & $\begin{array}{l}\text { Two active switch ac- } \\
\text { dc/dc-dc boost converter }\end{array}$ \\
\hline \multicolumn{2}{|c|}{ Number of active switch } & $3^{*}$ & 1 & 2 \\
\hline \multicolumn{2}{|c|}{ Number of diodes } & 3 & 6 & 5 \\
\hline \multicolumn{2}{|c|}{ Possibility of Shoot-through fault } & Possible & Impossible & Impossible \\
\hline \multicolumn{2}{|c|}{ Voltage stress on the switches } & Full dc bus voltage & Half dc bus voltage & Half dc bus voltage \\
\hline \multicolumn{2}{|c|}{ Efficiency } & Low & High & Highest \\
\hline \multirow{2}{*}{$\begin{array}{l}\text { Capability of } \\
\text { balancing dc bus } \\
\text { capacitor voltages }\end{array}$} & Normal mode & Possible & Possible & Possible \\
\hline & Battery mode & Impossible & Impossible & Possible \\
\hline
\end{tabular}

*Note: Switch S3 for charging the battery is not counted for a fair comparison. 


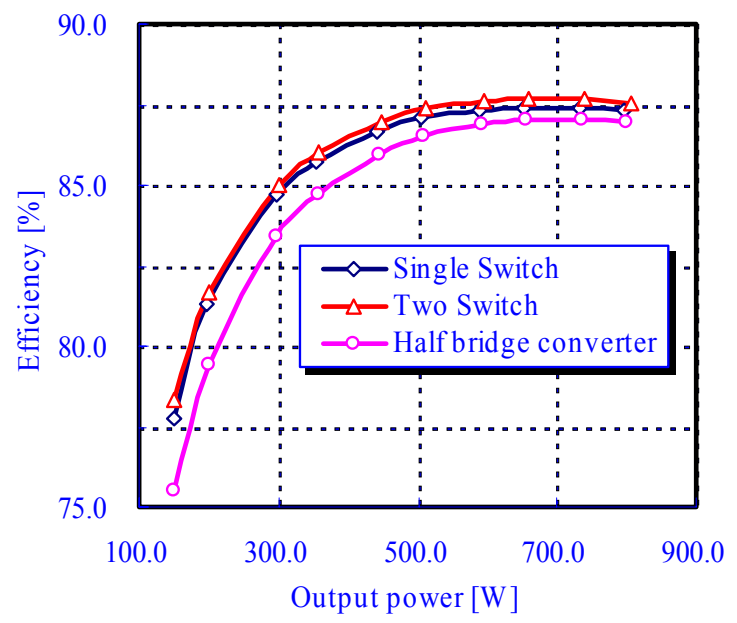

Fig.6 Comparison of measured efficiency vs. output power.

These experimental results confirm the previous analysis with regard to current distortion factor, power factor and efficiency.

To demonstrate the dc bus capacitors' voltage balancing capability of the two-switch boost converter, Fig. 7 shows typical waveforms of output voltage, output current and dc bus capacitor voltages for an unbalanced load. Fig. 7(a) is for normal operation and (b) is for battery powered operation with a rated battery voltage of $48 \mathrm{~V}$. It can be seen that although the load draws different currents for positive and negative half cycles, voltages across the upper or lower capacitor are well balanced, and thus a balanced output voltage is obtained.

\section{CONCLUSIONS}

The advantages of the single- and two-switch boost converters over the conventional half-bridge converter for power factor correction in UPS applications can be summarized as follows;

- Fewer active switches,

- Reduced voltage stress on the switches and diodes in the boost converter,

- Improved efficiency and reliability.

The two-switch boost converter provides an additional feature, the capability of voltage balancing control for the dc bus capacitors, which makes it suitable for a wide variety of applications.

Since the cost of diodes is much lower than that of switching devices like IGBTs, the cost penalty caused by the increased number of diodes in the boost converters is more than offset by the reduced number of active switches.

\section{REFERENCES}

[1] M. Nakamura, Y. Fujitani and S. Kawauchi, "Several Recent Circuits in the Small Power UPS System", National Convention Record, IEE IAS Japan (JIASC), vol. 2, No. S-1-2-2, 1995.

[2] K. Kuroki, "The Main Circuit Configuration of UPS", JIASC, vol. 2, No.S.1-3, 1995
[3] R. Krishnan, "Design and Development of a High Frequency On-Line Uninterruptible Power Supply", IEEE IECON, vol. 1, pp. 578-583, 1995.

[4] K. Hirachi, et al, "Cost-Effective Practical Developments of HighPerformance and Multi-Functional UPS with New System Configurations and Their Specific Control Implementations", IEEE PESC, pp. 480-485, 1995.

[5] K. Hirachi, et al, "Practical Developments of High-Performance UPS with New System Configurations and Their Specific Control Implementations", IPEC-Yokohama, pp. 1278-1283, 1995.

[6] G.J. Su and T. Ohno, "A New Topology for Single Phase UPS Systems", Conf. Record of PCC-Nagaoka, August 1997.

[7] G.J. Su and T. Ohno, "A Novel Topology for Single Phase UPS Systems", Conf. Record of IEEE IAS , pp. 1376-1382, October 1997.

[8] G.J. Su, "Design and Analysis of a Low Cost, High Performance Single Phase UPS System", APEC, vol. 2, pp. 900-906, 2001.
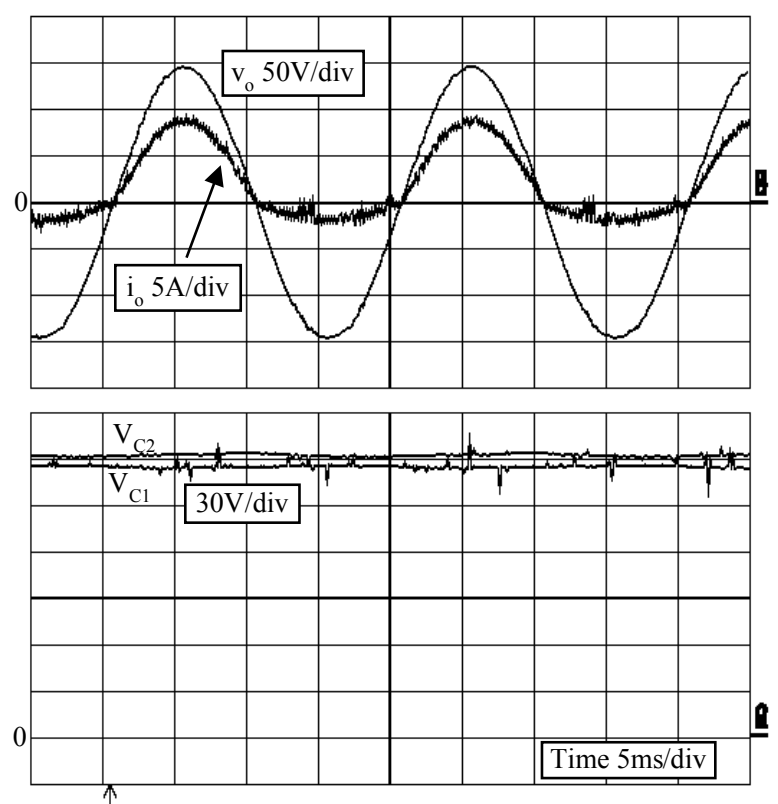

(a) Normal Operation
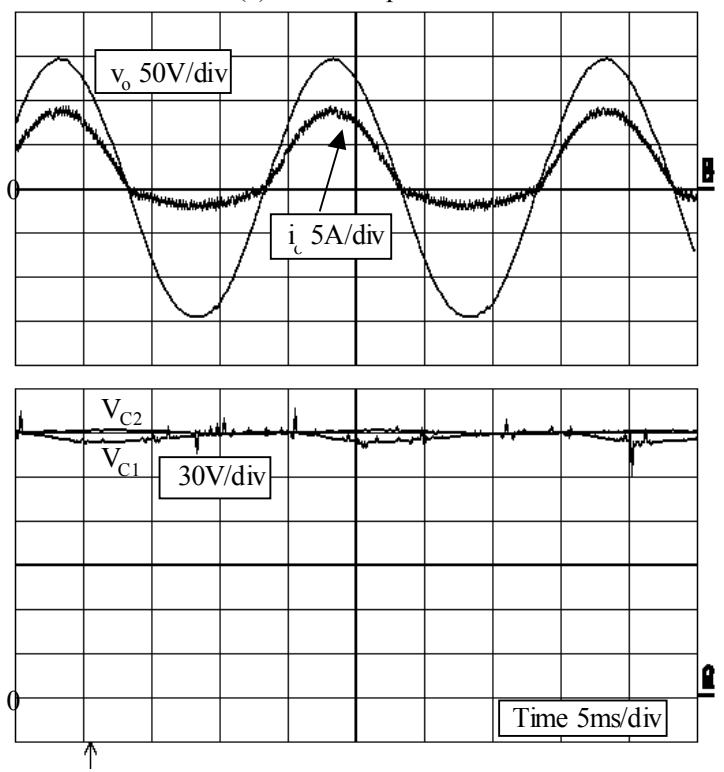

(b) Battery powered operation

Fig. 7 Typical waveforms for an unbalanced load with the two-switch boost converter, showing balanced dc capacitor voltages. 